
\title{
$\begin{array}{ll}\text { Research Square } & \begin{array}{l}\text { Preprints are preliminary reports that have not undergone peer review. } \\ \text { They should not be considered conclusive, used to inform clinical practice, } \\ \text { or referenced by the media as validated information. }\end{array}\end{array}$ \\ Biodiesel production from vegetable oil refinery waste using ohmic-assisted esterification
}

\section{Afsaneh Alishahi}

Shiraz University School of Agriculture

MEHRDAD NIAKOUSARI ( $\nabla$ mehrnia2012@yahoo.com )

Shiraz University School of Agriculture https://orcid.org/0000-0002-4557-9031

Mohammad Taghi Golmakani

Shiraz University School of Agriculture

\section{Research Article}

Keywords: Ohmic, Vegetable oil refinery waste, Esterification, Biodiesel

Posted Date: May 17th, 2021

DOI: https://doi.org/10.21203/rs.3.rs-526966/v1

License: (c) (i) This work is licensed under a Creative Commons Attribution 4.0 International License.

Read Full License 
Biodiesel production from vegetable oil refinery waste using ohmic-assisted esterification

\section{Afsaneh Alishahi, Mehrdad Niakousari*, Mohammad-Taghi Golmakani}

Food Science and Technology Department, School of Agriculture, Shiraz University, Shiraz, Iran

\section{*Corresponding Author:}

Mehrdad Niakousari, Ph.D.,

Professor, Food Science and Technology Department, School of Agriculture, Shiraz

University, Shiraz, Postal Code 71441-65186, Iran.

E-mail: niakosar@shirazu.ac.ir; mehrnia2012@yahoo.com

Tel: $+98-71-36138246 ;+98-9173001030$

Fax: $+98-71-32286110$ 


\begin{abstract}
The ohmic-assisted esterification method was compared and contrasted with the conventional esterification method for biodiesel (fatty acid methyl esters) production from vegetable oil refinery waste containing high free fatty acids. The reaction variables were free fatty acid:methanol molar ratio $(1: 1,1: 5,1: 10$, and $1: 15)$, catalyst concentration $(1 \%, 2 \%$, and $3 \%)$ and reaction time $(5,30$, and $60 \mathrm{~min})$. By increasing the conversion yield of free fatty acids to fatty acid methyl esters, density increased while viscosity and refractive index decreased. Optimum reaction conditions were a molar ratio of $1: 10$ and a catalyst concentration of $3 \%$ after 60 min of esterification reaction, while having a $95.74 \%$ conversion yield. There was no significant difference between fatty acid methyl esters produced with ohmic-assisted esterification and conventional esterification methods in terms of fatty acid profile, physicochemical and heating properties. Meanwhile, energy consumption by the conventional esterification method was about $25 \%$ higher than that of ohmic-assisted esterification. In fact, ohmic-assisted esterification can be considered as a green, cost-effective alternative method for the production of biodiesel from vegetable oil refinery waste.
\end{abstract}

Keywords: Ohmic; Vegetable oil refinery waste; Esterification; Biodiesel 


\section{Introduction}

Ohmic heating (direct resistance heating) is a developed process that has appeared over the past two decades. It involves the simultaneous heating of liquid or solid materials by passing an electric current through [1]. The electrical conductivity of the materials is an essential property that affects the ohmic heating rate, which is mainly a function of chemistry and structure of the substances [2]. The electrical conductivity is also affected by parameters such as free water and ionic strength. The presence of non-polar constituents such as lipids decreases conductivity, while the presence of ionic substances like acids and salts increases electrical conductivity [3]. The advantage of ohmic heating is its uniform heating distribution, which makes it an applicable process for various waste treatments such as sterilization of animal wastes, heating of slurries, compost leachate, and sewage sludge. Furthermore, ohmic heating can be used for heating chemical reactions such as esterification. Wastes and reactants in chemical reactions could rapidly and effectively be heated from ambient temperature to the boiling point by ohmic heating process $[4,5]$.

Biodiesel is a renewable, non-toxic, and biodegradable substitute for petroleum-based diesel fuel. In the industrial scale of biodiesel production, transesterification is the most common reaction for producing fatty acid methyl esters (FAMEs) from vegetable oils [6]. However, this reaction is highly susceptible to the presence of free fatty acids (FFAs) and initiates the saponification reaction, thereby preventing FAMEs production. Acid-catalyzed esterification is another reversible reaction in which free fatty acid (FFA) and alcohol react in the presence of the acid catalyst to produce water and fatty acid methyl ester (FAME). Acid-catalyzed esterification can perform as a pre-treatment of transesterification or as an independent method for production of FAMEs from raw materials containing high FFAs [7].

Vegetable oils such as soybean, rapeseed, and sunflower are the most common used raw materials for FAMEs production, but usually their costs exceed that of petroleum fossil diesel 
fuel [8]. In recent years, many researchers have suggested that oil wastes can be substitutes to virgin and edible vegetable oils. They have advantages such as reducing production costs, not competing with the food market, and recycling wastes [9]. Fifteen million tons of waste frying/cooking oils are dumped worldwide annually that can be a good alternative raw material for production of FAMEs. However, collecting such a waste is challenging due to sparsity of places like restaurants that produce it. In contrast, vegetable oil refinery plant waste is easily accessible [10].

The byproducts of edible oil refinery such as soapstocks, acid oils, and deodorized distillates can be suggested as alternatives and cheaper feedstocks for biodiesel production [11]. Alkali refining is one of the oil refinery plant processes which removes FFAs from different oils. In this process, the reaction of alkali solution (usually $\mathrm{NaOH}$ ) with FFAs leads to the formation of soap. Today, most oil refinery plants apply an acidulation process on soapstocks to produce acid oil (AO) containing high FFAs. AO can be used in animal feed, production of chemicals, and biodiesel [12]. The global production of vegetable oils in 2019 was 214 million tonnes [13]. On the other hand, the amount of AO produced in the oil refinery plants is up to $10 \%$ of the total refined vegetable oils. Meanwhile, AO price is less than $20 \%$ of edible oil, which makes it a potential feedstock for FAME production [11].

In current conditions, different methods such as conventional heating, oscillatory flow reactor, microwave and ultrasonic technologies have been studied in relation to FAME production from oil wastes. To the best of our knowledge, however, ohmic-assisted esterification (OAE) has not as yet been evaluated for biodiesel production from oil wastes. The objective of this study was to investigate the possibility of using ohmic process as a novel esterification method for producing FAMEs from oil refinery waste. Evaluations were made on the effects of process variables, namely acid oil to methanol molar ratio, reaction time, and catalyst concentration on FFA content, conversion yield, mass yield, and physicochemical properties of the produced 
FAMEs. Also, OAE was compared to the conventional esterification (CE) method in terms of energy consumption, physical and heating properties.

\section{Materials and methods}

\subsection{Materials}

All chemicals (solvents, reagents, and standards) used in the experiments were purchased from Merck (Darmstadt, Germany) and Sigma- Aldrich (St. Louis, MO). AO containing 51.54\% FFAs was acquired from the refinery waste of the Narges Shiraz Vegetable Oil Company.

\subsection{Preparation of oil refinery waste}

The oil refinery waste was centrifuged two times at $700 \mathrm{~g}$ for $15 \mathrm{~min}$ at $50{ }^{\circ} \mathrm{C}$ to remove impurities. The supernatant layer was separated as AO. Prior to acid-catalyzed esterification, AO was hydrolyzed by a magnetic stirrer (at $90{ }^{\circ} \mathrm{C}$ and a mixing speed of $400 \mathrm{rpm}$ for $24 \mathrm{~h}$ ) to convert all acylglycerols (monoacylglycerols, diacylglycerols, and triacylglycerols) to FFAs. For hydrolysis operation, equal weight of $\mathrm{AO}$ and distilled water were mixed and $2 \%$ concentrated sulfuric acid (98\%) was added to the mixture to accelerate the hydrolysis reaction and also to prevent soap formation. In addition, 200 ppm tertiary butylhydroquinone (TBHQ) was applied to prevent fatty acid oxidation [14]. Upon completion of the hydrolysis reaction, centrifugation was performed at $700 \mathrm{~g}$ for $15 \mathrm{~min}$. The supernatant layer was separated as hydrolyzed acid oil (HAO) and the water layer was discarded. Then, the remaining moisture in the $\mathrm{HAO}$ was removed by a magnetic stirrer at $60^{\circ} \mathrm{C}$.

\subsection{Physicochemical properties of HAO}

Physicochemical properties of the HAO including the FFA content ( $\mathrm{Ca} 5 \mathrm{a}-40)$, acid value $(\mathrm{Cd}$ 3d-63), saponification value (Cd 3a-94), density (1a-64), iodine value (Cd 1c-85), moisture 
content, and volatile matters ( $\mathrm{Ca} 2 \mathrm{c}-25)$ were determined based on the American Oil Chemists' Society (AOCS) Official Methods [15]. Due to HAO dark color, $1 \mathrm{~mL}$ of HAO was diluted with $9 \mathrm{~mL}$ ethanol and afterwards, AOCS Cc7-25 method was used to investigate the refractive index [15]. The kinematic viscosity (D445) was measured based on the American Society for Testing and Materials (ASTM) Official Method [16]. Gas chromatography/flame ionization detector (GC/FID) system was used to determine fatty acid composition. An internal standard (methyl heptadecanoate) was used to confirm the completion of the hydrolysis reaction and also to calculate purity of the HAO using Eq. (1) [17]:

Purity $(\%)=\left(\frac{\text { Area of FAMEs }}{\text { Area of internal standard }}\right) \times\left(\frac{\text { Weight of internal standard }(g)}{\text { Weight of FAMEs }(g)}\right) \times 100$

Electrical conductivity of the HAO was evaluated by a conductivity meter probe $(86555 \mathrm{AZ}$, Taichung, Taiwan). The color attributes (Lightness $\left(\mathrm{L}^{*}\right)$, redness-greenness $\left(\mathrm{a}^{*}\right)$, bluenessyellowness $\left.\left(b^{*}\right)\right)$ of the HAO were also evaluated [18].

\subsection{Acid-catalyzed esterification}

An ohmic reactor (Fig. 1) was designed for esterification of FFAs at $300 \mathrm{~V}$. OAE reaction was performed at different HAO:methanol molar ratios (1:1, 1:5, 1:10, and 1:15), sulfuric acid concentration $(1 \%, 2 \%$, and $3 \%$, based on $\mathrm{HAO}$ weight $)$, and reaction time $(5,30$, and $60 \mathrm{~min})$. According to Eq. (2), molecular weight $\left(\mathrm{MW}_{\mathrm{i}}\right)$ and mass fraction $\left(\mathrm{X}_{\mathrm{i}}\right)$ of fatty acid in the HAO was used to calculate the HAO molecular weight. Then, a desirable ratio of HAO to methanol was determined.

Molecular weight of $H A O=\sum\left(M W_{i} \times X_{i}\right)$

Thirty grams of samples containing methanol, HAO, and sulfuric acid were added to the ohmic reactor. A condenser was attached to the reactor to prevent methanol evaporation. A magnetic stirrer at a constant agitation speed of $400 \mathrm{rpm}$ was used to mix the reactants. Then, ohmicassisted acid-catalyzed esterification reaction was performed at $60{ }^{\circ} \mathrm{C}$. Also, optimum reaction 
condition of OAE method was compared with CE method (magnetic stirrer). Agitation speed and temperature in CE method kept constant at $400 \mathrm{rpm}$ and $60^{\circ} \mathrm{C}$, respectively.

When the reaction time reached an end, the samples were cooled to ambient temperature. The upper layers were separated and washed $3-5$ times with hot distilled water $\left(60{ }^{\circ} \mathrm{C}\right)$ to remove impurities and the catalyst. The water phases were discarded and supernatant phases constituting FAMEs were dried using a magnetic stirrer at the agitation speed of $400 \mathrm{rpm}$ and $60{ }^{\circ} \mathrm{C}$ [19]. Mass yield and conversion yield were calculated according to Eq. (3) and Eq. (4), respectively $[20,21]$ :

Mass yield $(\%)=\left(\frac{\text { Weight of FAMEs }(g)}{\text { Weight of HAO }(g)}\right) \times 100$

Conversion yield $(\%)=\left(\frac{N_{S o}-N_{S}}{N_{s o}}\right) \times 100$

where, $\mathrm{N}_{\mathrm{so}}$ and $\mathrm{N}_{\mathrm{s}}$ are FFA content $(\%)$ at the beginning and end of esterification reaction, respectively.

\subsection{Physicochemical properties of FAMEs}

Electrical conductivity (samples with and without acid catalysts), fatty acid composition, density, kinematic viscosity, refractive index, and color attributes $\left(\mathrm{L}^{*}, \mathrm{a}^{*}\right.$, and $\left.\mathrm{b}^{*}\right)$ of produced FAMEs were investigated based on the methods described in section 2.3.

\subsection{Evaluation of produced FAMEs under optimum condition}

A non-contact infrared thermometer was used for measuring the temperature of reactants in OAE and CE methods. Cloud point (D2500), fire point (D92), flash point (D92), and pour point (D97) of FAMEs were analyzed based on the ASTM Official Methods [16]. Eq. (1), which mentioned in the section 2.3 was used to determine the purity of FAMEs. Final yield and energy consumption of acid-catalyzed esterification reaction, washing, and drying were calculated 
based on the Eq. (5) and Eq. (6), respectively. Also, specific energy consumption for producing

$1 \mathrm{~kg}$ FAMEs was determined according to Eq. (7) [20, 22]:

Final yield $(\%)=\frac{\text { FAMEs purity }(\%) \times \text { Mass yield }(\%)}{100}$

Energy consumption $(k W h)=$ Power $(k W) \times$ Time $(h)$

Specific energy consumption $(\mathrm{kWh} / \mathrm{kg})=\frac{\text { Energy consumption }(\mathrm{kWh})}{\text { Weight of final FAMEs }(\mathrm{kg})}$

\subsection{Statistical analysis}

The experiments were conducted in triplicate and the results were reported as mean values \pm standard deviation. The results were analyzed by ANOVA analysis using SAS (Statistical Analysis Software, version 9.1; SAS Institute Inc. Cary, NC). Duncan's Multiple Range test was performed to assess the significant differences $(P<0.05)$ among mean values.

\section{Results and discussion}

\subsection{Physicochemical properties of HAO}

Table 1 shows the physicochemical properties of the HAO. The moisture and volatile matters of $\mathrm{HAO}$ were reduced to $0.08 \%$ after the drying process, which made it suitable for acidcatalyzed esterification. The FFA content and purity of the HAO were $87.39 \%$ and $87.68 \%$, respectively. One of the most critical problems in applying AO for FAME production is the presence of contaminants in the raw materials which reduce the final purity of the produced biodiesel [23]. Despite a complete conversion of acylglycerols to FFAs, the results showed that the HAO, as used in this study, contained $12.32 \%$ contaminants. Similarly, Kulkarni et al. [24] reported that AO contained $8.6 \%$ of unsaponifiable matters. Also, Wang et al. [23] reported that $\mathrm{AO}$ contained $75.5 \%$ acylglycerols and FFAs, $0.8 \%$ water and $23.7 \%$ of inert materials.

\subsection{Evaluation of different OAE variables on FAMEs yield}




\subsubsection{HAO to methanol molar ratio}

At a HAO:methanol molar ratio of 1:1 (with 1\%,2\%, and 3\% catalyst concentration), no current was established or detected in the ohmic reactor and the initial temperature of the samples remained constant $\left(35^{\circ} \mathrm{C}\right)$. According to the electrically-neutral nature of the oil molecules, there was no increase of temperature in the reaction media [1]. Few reports are available on acid-catalyzed esterification reactions at ambient temperature but, in general, biodiesel is often produced at $60^{\circ} \mathrm{C}$ to $70{ }^{\circ} \mathrm{C}$ [6]. In our study, $60^{\circ} \mathrm{C}$ was selected as a constant temperature for OAE reaction. Nonetheless, at the HAO:methanol molar ratio of $1: 1$, the temperature did not reach $60{ }^{\circ} \mathrm{C}$. Thus, no data was reported for HAO:methanol molar ratio of $1: 1$.

By increasing HAO:methanol molar ratio from 1:1 to 1:5, an electrical current was established and the temperature of reactants reached $60{ }^{\circ} \mathrm{C}$. Fig. 2a shows the effects of HAO:methanol molar ratio (without acid catalyst) on electrical conductivity. By increasing the HAO:methanol molar ratio from 1:5 to $1: 15$, the electrical conductivity increased from 45.3 to $135.56 \mu \mathrm{S} / \mathrm{cm}$, which shows how methanol can affect the establishment of electrical currents without the presence of the catalyst. In fact, increasing methanol as a polar solvent in the reaction media can increase the electrical conductivity [25].

The effects of HAO to methanol molar ratio on FFA content, conversion yield, and mass yield are presented in Table 2. By increasing HAO:methanol molar ratio from 1:5 to 1:15, the amount of FFAs decreased, while conversion yield increased. Although the highest conversion yield $(97.13 \%)$ and the lowest FFA content $(2.51 \%)$ were obtained at the HAO:methanol molar ratio of 1:15, there was no significant difference between HAO:methanol molar ratio of 1:15 and 1:10. Therefore, HAO:methanol molar ratio of 1:10 was selected as an optimum condition. Similar to our results, Hayyan et al. [26] showed that when the sludge palm oil:methanol molar ratio increased from 1:8 to 1:14, no significant change was observed in the reduction of FFA. 
Also, Peng et al. [27] reported that further increase in oil:methanol molar ratio of 1:9 showed very limited impact on the yield of FAMEs.

As seen in Table 2, mass yield decreased by increasing the HAO:methanol molar ratio. The lowest mass yield (92.32\%) was observed when HAO:methanol molar ratio was 1:15. Despite the fact that methanol in excess amounts can help shift the equilibrium towards product formation, more washing steps after reaction is required until the washing outlet water becomes transparent [28]. As the HAO:methanol molar ratio increased from 1:5 to 1:15, the washing steps were increased from 3 to 5 times to ensure complete removal of methanol. During washing and separation of water from FAMEs using a separation funnel, some FAMEs were separated with water, which were visible to the naked eyes.

\subsubsection{Catalyst concentration}

Table 2 shows the effects of sulfuric acid concentration as a catalyst on FFA content, conversion yield, and mass yield. With increasing sulfuric acid concentration from $1 \%$ to $3 \%$, there was an increase in conversion yield, whereas FFA content decreased significantly. The highest conversion yield $(97.13 \%)$ was observed when OAE was carried out with $3 \%$ catalyst concentration. However, the catalyst concentration had no effect on the mass yield. Fig. 2b shows that the acid content affected the electrochemical properties of the HAO:methanol mixture and, by increasing catalyst concentration from $1 \%$ to $3 \%$, the electrical conductivity increased. The presence of sulfuric acid in the OAE was a key factor in our study. Despite the high electrical resistance of HAO to the passage of current, sulfuric acid established electrical current and the temperature increased up to $60{ }^{\circ} \mathrm{C}$ [1]. Therefore, sulfuric acid concentration of $3 \%$ was considered as an optimum catalyst concentration. This finding is in accordance with an earlier study by Peng et al. [27] in claiming that an increase in catalyst concentration from $1 \%$ to $3 \%$ causes a marked increase in FAME yield. However, a further increase in catalyst 
concentration to 5\% leads to an insignificant increase in FAME yield and reaction rate. According to Wang et al. [29], no sufficient increase in the amount of conversion occurred when the amount of acid catalyst exceeded $4 \%$.

\subsubsection{Reaction time}

Table 2 shows the effect of reaction time on FFA content, conversion yield, and mass yield. Although reaction time had no significant effect on the mass yield, it showed significant effects on reducing FFA content and increasing conversion yield. At the reaction time of $60 \mathrm{~min}$, the highest conversion yield $(97.13 \%)$ and the lowest FFA content $(2.51 \%)$ were observed. Therefore, $60 \mathrm{~min}$ reaction time was selected as the optimum reaction time. Various studies have confirmed that the rate of the reaction is slow at the early stages of the esterification reaction due to the mixing and dispersion of alcohol into the oil, but afterwards, and similar to our findings, the reaction proceeds very fast and FFAs conversion to FAMEs reaches a maximum, and then remains relatively constant [30].

\subsection{Evaluation of OAE variables on FAMEs properties}

Effect of different OAE variables on FAMEs properties are presented in Table 3 and Table 4. High viscosity of FAMEs causes some problems in the engine. By increasing viscosity, the required energy for pumping the fuel and deposits increases. It also causes more problems in the cold weather, due to the higher viscosity at the lower temperature [31]. The results showed that by increasing reaction time, catalyst concentration, and methanol to HAO molar ratio, the kinematic viscosity decreased significantly (Table 3). Between the conversion yield and kinematic viscosity, a negative correlation was obtained $\left(y=-9.325 x+150.2, R^{2}=0.978\right)$. HAO:methanol molar ratio of $1: 15,3 \%$ catalyst concentration, and 60 min reaction time reduced the viscosity to $6.004 \mathrm{~mm}^{2} / \mathrm{s}$, while the viscosity of the HAO was $41.510 \mathrm{~mm}^{2} / \mathrm{s}$. 
Density is another important property of the fuel that affects the engine performance characteristics such as cetane number and heating value [31]. As seen in Table 3, densities of the FAMEs varied from $874.8582-882.4584 \mathrm{~kg} / \mathrm{m}^{3}$. By increasing reaction time, catalyst concentration, and methanol to HAO molar ratio, higher densities were observed. The correlation between the conversion yield and density was positive $\left(\mathrm{y}=6.25 \mathrm{x}-5415, \mathrm{R}^{2}=\right.$ 0.957). The highest density $\left(882.4584 \mathrm{~kg} / \mathrm{m}^{3}\right)$ was observed when the OAE with the highest values of variables was applied.

The HAO had the refractive index of 1.3740. After OAE, however, at its highest variable levels (HAO:methanol molar ratio of 1:15, catalyst concentration of 3\%, and reaction time of $60 \mathrm{~min}$ ), the refractive indices of FAMEs decreased to their lowest value (1.3711) (Table 3). A negative correlation existed between the conversion yield and refractive index $(y=-2.925 e+4 x+$ 4.021e+4, $\left.\mathrm{R}^{2}=0.950\right)$. Similarly, Dehghan et al. [22] reported that refractive index is a trustworthy property for predicting the progress of the transesterification reaction.

FAMEs color varies from crystal clear to black depending on the oil type and contaminants present in it. Wastes such as fried oils are dark and transesterification can brighten their color [32]. As shown in Table 4, the highest value of $\mathrm{L}^{*}(63.00)$ and the lowest values of $\mathrm{a}^{*}(16.00)$ and $b^{*}$ (39.67) were observed when the OAE with the highest values of variables was applied. Results showed that acid-catalyzed esterification reaction of HAO can significantly brighten its color. This finding is in accordance with the similar study conducted for transesterification of inedible olive oil [22]. Based on the above-mentioned results, it can be inferred that there is a meaningful relationship between the conversion yield of produced FAMEs and their physical properties.

\subsection{Comparing OAE with CE}

\subsubsection{Yield}


In both esterification methods, the amounts of FFAs were markedly reduced, while this reduction in the OAE was insignificantly higher (Fig. 3). In both OAE and CE methods, the FFAs were reduced from $87.39 \%$ to less than $5 \%$, indicating that the both methods are suitable for acid-catalyzed esterification reaction, which is often used as a pre-treatment before transesterification of waste oils containing higher than 5-7\% FFAs [19].

According to Fig. 3, for both esterification methods, no significant differences were observed in terms of conversion yield, mass yield, purity, and final yield. In OAE and CE methods, the temperature reached up to $60{ }^{\circ} \mathrm{C}$ after 75 and 97 seconds, respectively and then remained constant (Fig. 4). Accordingly, in CE method, the temperature reached to $60{ }^{\circ} \mathrm{C}$ only 22 seconds after OAE method. Since there were no significant differences between temperature profiles of both esterification methods, it seems logical that their conversion yields are similar.

\subsubsection{Physicochemical properties}

No significant differences were observed in physical properties, fatty acid composition, and heating properties of $\mathrm{OAE}$ and $\mathrm{CE}$ methods, which can be related to the lack of differences between conversion yield of both esterification methods (Table 5). According to the ASTM D6751 Official Method, the minimum flash point of biodiesel is $130{ }^{\circ} \mathrm{C}$ [16]. In the light of this, both methods were complied with the standard. Furthermore, the ASTM D445 Official Method is indicative of an acceptable limit range of kinematic viscosity $\left(1.9-6.0 \mathrm{~mm}^{2} / \mathrm{s}\right)$ which confirms that both methods are within the standard range [16]. The densities of FAMEs produced by OAE and CE were $882.2117 \mathrm{~kg} / \mathrm{m}^{3}$ and $882.3224 \mathrm{~kg} / \mathrm{m}^{3}$, respectively, which are in accordance with a previous study by Alptekin and Canakci [31] in stating that the density of biodiesel usually varies between $0.86 \mathrm{~g} / \mathrm{cm}^{3}$ and $0.90 \mathrm{~g} / \mathrm{cm}^{3}$. The $\mathrm{L}^{*}$ value of HAO was 44.33, whereas OAE and CE methods led to an increase of this value to 62.00 and 61.67 , respectively. 
Although color is not a major characteristic of biodiesel quality, increasing the $\mathrm{L}^{*}$ value in esterification reaction indicates an increase in conversion yield [32].

\subsubsection{Energy consumption}

The main difference between acid-catalyzed OAE and CE methods was the energy consumption (Table 5). Energy consumption of OAE and CE methods were $0.050 \mathrm{kWh}$ and $0.070 \mathrm{kWh}$, respectively. OAE showed lower specific energy consumption $(5.167 \mathrm{kWh} / \mathrm{kg})$ in comparison with CE $(6.686 \mathrm{kWh} / \mathrm{kg})$. The ohmic method led to a rapid and uniform heating of liquids with high energy conversion efficiency [33]. In the ohmic reactor, the energy is dissipated directly into the reaction mixture [25]. An electric current is passed through the heating sample, resulting in a temperature rise due to the conversion of the electric energy into the heat [4]. On the other hand, in the conventional heating method, the heat energy is generated externally and then transferred to the reactants via conduction and convection, which results in a slow and non-uniform heating and, consequently, the occurrence of an inefficient process [3].

\section{Conclusion}

The main purpose of this study was to evaluate the possibility of using ohmic heating process for acid-catalyzed esterification reaction. This was aimed at using vegetable oil refinery waste and converting their FFAs to FAMEs. The results showed that the ohmic heating can convert 95.74\% of FFAs to FAMEs in one hour at an HAO:methanol molar ratio of 1:10, along with $3 \%$ catalyst concentration, which is considered as an optimum condition. By increasing the FAMEs in OAE, the viscosity and refractive index decreased, whereas density increased. Also, by increasing the conversion percentage, the final product became brighter. In comparing OAE and CE, no significant differences were observed in physicochemical properties of the FAMEs being produced. The only significant difference was observed in energy consumption, which 
was higher in the CE method in comparison with the OAE method. In fact, OAE can be proposed as a cost-effective alternative method for FAMEs production from oil refinery waste. However, this emerging technology needs to be further investigated for a possible scaling-up of biodiesel production.

\section{Ethics approval}

This manuscript has not been previously published and is not under consideration in the same form in any other peer-reviewed journal and will not be submitted elsewhere unless a rejection decision is made by this journal.

\section{Acknowledgement - Funding}

The authors gratefully acknowledge the financial support of the Research Affairs Office at Shiraz University (Grant \# 93GCU1M1981).

\section{Declaration of interests}

\The authors declare that they have no known competing financial interests or personal relationships that could have appeared to influence the work reported in this paper.

\section{The authors:}

Afsaneh Alishahi

- Formal analysis, Investigation, Methodology, Writing-original draft

Mehrdad Niakousari (Corresponding author)

- Conceptualization, Investigation, Supervision, Writing-review \& editing

Mohammad Taghi Golmakani

- Investigation, Supervision 


\section{References}

[1] Makroo HA, Rastogi NK, Srivastava B (2020) Ohmic heating assisted inactivation of enzymes and microorganisms in foods: A review. Trends Food Sci Technol 97:451-465. https://doi.org/10.1016/j.tifs.2020.01.015

[2] Gavahian M, Tiwari BK, Chu YH, Ting Y, Farahnaky A (2019) Food texture as affected by ohmic heating: Mechanisms involved, recent findings, benefits, and limitations. Trends Food Sci Technol 86:328-339. https://doi.org/10.1016/j.tifs.2019.02.022

[3] Varghese KS, Pandey MC, Radhakrishna K, Bawa, AS (2012) Technology, applications and modelling of ohmic heating: a review. J Food Sci Technol 51(10):2304-2317. https://doi.org/10.1007/s13197-012-0710-3

[4] Sakr M, Liu S (2014) A comprehensive review on applications of ohmic heating (OH). Renew Sustain Energy Rev 39:262-269. https://doi.org/10.1016/j.rser.2014.07.061

[5] Zare M, Golmakani MT, Sardarian A (2020) Green synthesis of banana flavor using different catalysts: a comparative study of different methods. Green Chem Lett Rev 13(2):8291. https://doi.org/10.1080/17518253.2020.1737739

[6] Zahan KA, Kano M (2018) Biodiesel production from palm oil, its by-products, and mill effluent: a review. Energies 11(8):2132. https://doi.org/10.3390/en11082132

[7] Ganesan S, Nadarajah S, Shamsudin NN, Khairuddean M, Teh, GB (2020). Esterification of palm fatty acid distillate using ammonium ferric sulfate-calcium silicate as a heterogeneous acid catalyst. Bioenergy Res 13:1297-1307. https://doi.org/10.1007/s12155-020-10143-6

[8] Ataya F, Dubé MA, Ternan M (2007) Acid-catalyzed transesterification of canola oil to biodiesel under single and two-phase reaction conditions. Energy Fuels 21(4):2450-2459. https://doi.org/10.1021/ef0701440 
[9] Outili N, Kerras H, Nekkab C, Merouani R., Meniai AH (2020) Biodiesel production optimization from waste cooking oil using green chemistry metrics. Renew Energy 145:25752586. https://doi.org/10.1016/j.renene.2019.07.152

[10] Lee AF, Bennett JA, Manayil JC, Wilson K (2014) Heterogeneous catalysis for sustainable biodiesel production via esterification and transesterification. Chem Soc Rev 43(22):78877916. https://doi.org/10.1039/C4CS00189C

[11] Zou HS, Chai J (2017) A novel ultrasonic reactor for continuous production of biodiesel from waste acid oil. Korean J Chem Eng 34(2):353-359. https://doi.org/10.1007/s11814-016$\underline{0280-6}$

[12] Shahidi F (2005) Bailey's industrial oil and fat products. John Wiley \& Sons, Hoboken [13] OECD/FAO (2020) OECD-FAO Agricultural Outlook 2020. OECD Agriculture Statistics (database). https://doi.org/10.1787/4919645f-en. Accessed 12 August 2020

[14] Beker SA., da Silva YP, Bücker F, Cazarolli JC, de Quadros PD, Peralba MDCR, Piatnicki CMS, Bento FM (2016) Effect of different concentrations of tert-butylhydroquinone (TBHQ) on microbial growth and chemical stability of soybean biodiesel during simulated storage. Fuel 184:701-707. https://doi.org/10.1016/j.fuel.2016.07.067

[15] AOCS (2000) Official Methods and Recommended Practices of the American Oil Chemists' Society. AOCS press, Champaign

[16] ASTM (2013) Standard Specification for Biodiesel Fuel Blend Stock (B100) for Middle Distillate Fuels. ASTM International, West Conshohocken

[17] Golmakani MT, Rezaei K, Mazidi S, Razavi SH (2012) Effect of alternative $\mathrm{C}_{2}$ carbon sources on the growth, lipid, and $\gamma$-linolenic acid production of spirulina (Arthrospira platensis). Food Sci Biotechnol 21(2):355-363. https://doi.org/10.1007/s10068-012-0047-8 
[18] Gavahian M, Chu YH, (2018) Ohmic accelerated steam distillation of essential oil from lavender in comparison with conventional steam distillation. Innov Food Sci Emerg Technol 50:34-41. https://doi.org/10.1016/j.ifset.2018.10.006

[19] Gerpen JV (2010) Biodiesel from vegetable oils. In: Vertès AA, Qureshi N, Yukawa H, Blaschek HP (ed) Biomass to biofuels: strategies for global industries, 1st edn. John Wiley \& Sons, Chichester, pp 141-160

[20] Lin YC, Hsu KH, Lin JF (2014) Rapid palm-biodiesel production assisted by a microwave system and sodium methoxide catalyst. Fuel 115:306-311. https://doi.org/10.1016/j.fuel.2013.07.022

[21] Li H, Lv P, Wang Z, Miao C, Yuan Z (2020) Biodiesel continuous esterification process experimental study and equipment design. Biomass Convers Biorefin. https://doi.org/10.1007/s13399-020-00623-2

[22] Dehghan L, Golmakani M T, Hosseini SMH (2019) Optimization of microwave-assisted accelerated transesterification of inedible olive oil for biodiesel production. Renew Energy 138:915-922. https://doi.org/10.1016/j.renene.2019.02.017

[23] Wang ZM, Lee JS, Park JY, Wu CZ, Yuan ZH (2007) Novel biodiesel production technology from soybean soapstock. Korean J Chem Eng 24(6):1027-1030. https://doi.org/10.1007/s11814-007-0115-6

[24] Kulkarni BM, Pujar BG, Shanmukhappa S (2008) Investigation of acid oil as a source of biodiesel. Indian J Chem Technol 15(5):467-471

[25] Kaur N, Singh AK (2016) Ohmic heating: concept and applications-a review. Crit Rev Food Sci Nutr 56(14):2338-2351. https://doi.org/10.1080/10408398.2013.835303 
[26] Hayyan A, Alam MZ, Mirghani ME, Kabbashi NA, Hakimi NINM, Siran YM, Tahiruddin S (2011) Reduction of high content of free fatty acid in sludge palm oil via acid catalyst for biodiesel production. Fuel Process Technol 92(5):920-924. https://doi.org/10.1016/j.fuproc.2010.12.011

[27] Peng BX, Shu Q, Wang JF, Wang GR, Wang DZ, Han MH (2008) Biodiesel production from waste oil feedstocks by solid acid catalysis. Process Saf Environ Prot 86(6):441-447. https://doi.org/10.1016/j.psep.2008.05.003

[28] Hussain Z, Kumar R (2018) Esterification of free fatty acids: experiments, kinetic modeling, simulation \& optimization. Int $\mathrm{J}$ Green Energy 15(11):629-640. https://doi.org/10.1080/15435075.2018.1525736

[29] Wang Y, Ou S, Liu P, Xue F, Tang S (2006) Comparison of two different processes to synthesize biodiesel by waste cooking oil. J Mol Catal A Chem 252:107-112. https://doi.org/10.1016/j.molcata.2006.02.047

[30] Leung DY, Wu X, Leung MKH (2010) A review on biodiesel production using catalyzed transesterification. Appl energy 87(4):1083-1095.

https://doi.org/10.1016/j.apenergy.2009.10.006

[31] Alptekin E, Canakci M (2008) Determination of the density and the viscosities of biodiesel-diesel fuel blends. Renew Energy 33(12):2623-2630. https://doi.org/10.1016/j.renene.2008.02.020

[32] Bello EI (2016) Effects of transesterification on the colour of biodiesel. Sci Agric 13(1):10-13

[33] Gavahian M, Farahnaky A, Farhoosh R, Javidnia K, Shahidi F (2015) Extraction of essential oils from Mentha piperita using advanced techniques: Microwave versus ohmic 
assisted hydrodistillation. Food $\quad$ Bioprod $\quad$ Process $\quad$ 94:50-58.

https://doi.org/10.1016/j.fbp.2015.01.003

Table 1

Physicochemical properties of the hydrolyzed acid oil (HAO)

\begin{tabular}{lc}
\hline Physicochemical property & Value \\
\hline Free fatty acid $(\%)$ & $87.39 \pm 0.04^{* *}$ \\
Purity & $87.68 \pm 0.32$ \\
Acid value $(\mathrm{mg} \mathrm{KOH} / \mathrm{g})$ & $173.84 \pm 0.01$ \\
Saponification value $(\mathrm{mg} \mathrm{KOH} / \mathrm{g})$ & $192.36 \pm 2.59$ \\
Refractive index & $1.3740 \pm 0.0004$ \\
Density $\left(\mathrm{kg} / \mathrm{m}^{3}\right)$ & $870.1839 \pm 0.0827$ \\
Moisture and volatile matters $(\%)$ & $0.08 \pm 0.00$ \\
Iodine value & $66.09 \pm 1.38$ \\
Kinematic viscosity $\left(\mathrm{mm}^{2} / \mathrm{s} ; 40^{\circ} \mathrm{C}\right)$ & $41.510 \pm 0.028$ \\
Electrical conductivity $(\mu \mathrm{S} / \mathrm{cm})$ & $0.39 \pm 0.01$ \\
Color attribute & \\
$\mathrm{L}^{*}$ & $44.33 \pm 1.53$ \\
$\mathrm{a}^{*}$ & $29.00 \pm 1.00$ \\
$\mathrm{~b}^{*}$ & $49.67 \pm 1.53$ \\
Fatty acid composition $(\%)$ & \\
Lauric acid & $0.57 \pm 0.03$ \\
Myristic acid & $1.42 \pm 0.07$ \\
Palmitic acid & $42.53 \pm 0.46$ \\
Stearic acid & $1.81 \pm 0.05$ \\
Oleic acid & $29.06 \pm 0.38$ \\
Linoleic acid & $24.20 \pm 0.42$ \\
$\alpha$-Linolenic acid & $1.13 \pm 0.04$ \\
\hline
\end{tabular}

${ }^{* * *}$ Mean \pm standard deviation $(n=3)$. 
Table 2

Effects of different variables on free fatty acid content and yield in ohmic-assisted esterification (OAE) of hydrolyzed acid oil (HAO)

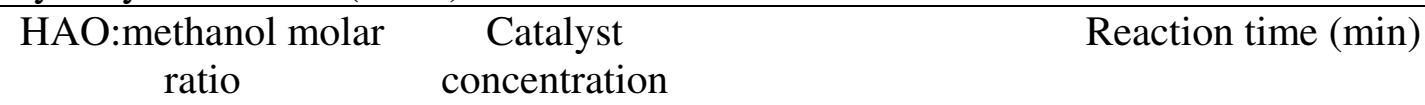

$(\%)$

5060

\begin{tabular}{|c|c|c|c|c|}
\hline \multicolumn{5}{|c|}{ Free fatty acid (\%) } \\
\hline \multirow[t]{3}{*}{$1: 5$} & 1 & $45.59 \pm 0.42^{\mathrm{a}^{*}}$ & $19.64 \pm 0.39^{f}$ & $15.53 \pm 1.05^{\mathrm{h}}$ \\
\hline & 2 & $34.39 \pm 1.34^{\mathrm{c}}$ & $17.46 \pm 0.01^{\mathrm{g}}$ & $11.95 \pm 1.20^{\mathrm{i}}$ \\
\hline & 3 & $27.72 \pm 0.96^{\mathrm{d}}$ & $12.73 \pm 0.34^{\mathrm{i}}$ & $9.87 \pm 0.90^{\mathrm{j}}$ \\
\hline \multirow[t]{3}{*}{$1: 10$} & 1 & $38.27 \pm 1.29^{b}$ & $10.02 \pm 0.23^{\mathrm{j}}$ & $6.34 \pm 0.18^{\mathrm{kl}}$ \\
\hline & 2 & $28.39 \pm 1.53^{\mathrm{d}}$ & $7.91 \pm 0.62^{\mathrm{k}}$ & $3.04 \pm 0.43^{\mathrm{mn}}$ \\
\hline & 3 & $18.54 \pm 0.72^{\mathrm{fg}}$ & $5.77 \pm 0.53^{1}$ & $3.72 \pm 0.48^{\mathrm{mn}}$ \\
\hline \multirow[t]{3}{*}{$1: 15$} & 1 & $37.54 \pm 0.17^{b}$ & $9.72 \pm 0.10^{j}$ & $5.99 \pm 0.13^{1}$ \\
\hline & 2 & $25.85 \pm 1.30^{\mathrm{e}}$ & $4.63 \pm 0.35^{1 \mathrm{~m}}$ & $3.31 \pm 0.24^{\mathrm{mn}}$ \\
\hline & 3 & $18.60 \pm 1.40^{\mathrm{fg}}$ & $3.71 \pm 0.48^{\mathrm{mn}}$ & $2.51 \pm 0.27^{\mathrm{n}}$ \\
\hline \multicolumn{5}{|c|}{ Conversion yield (\%) } \\
\hline \multirow[t]{3}{*}{$1: 5$} & 1 & $47.81 \pm 0.49^{n}$ & $77.52 \pm 0.44^{\mathrm{i}}$ & $82.22 \pm 1.20^{\mathrm{g}}$ \\
\hline & 2 & $60.63 \pm 1.54^{1}$ & $80.01 \pm 0.02^{h}$ & $86.32 \pm 1.38^{\mathrm{f}}$ \\
\hline & 3 & $68.27 \pm 1.09^{\mathrm{k}}$ & $85.43 \pm 0.39^{f}$ & $88.71 \pm 1.03^{\mathrm{e}}$ \\
\hline \multirow[t]{3}{*}{$1: 10$} & 1 & $56.19 \pm 1.47^{\mathrm{m}}$ & $88.52 \pm 0.26^{\mathrm{e}}$ & $92.75 \pm 0.21^{\mathrm{cd}}$ \\
\hline & 2 & $67.50 \pm 1.75^{\mathrm{k}}$ & $91.16 \pm 1.02^{\mathrm{d}}$ & $96.53 \pm 0.47^{\mathrm{ab}}$ \\
\hline & 3 & $78.77 \pm 0.83^{\mathrm{hi}}$ & $93.39 \pm 0.61^{\mathrm{c}}$ & $95.74 \pm 0.55^{\mathrm{ab}}$ \\
\hline
\end{tabular}




\begin{tabular}{|c|c|c|c|c|}
\hline $1: 15$ & $\begin{array}{l}1 \\
2 \\
3\end{array}$ & $\begin{array}{c}57.02 \pm 0.19^{\mathrm{m}} \\
70.41 \pm 1.48^{\mathrm{j}} \\
78.70 \pm 1.61^{\mathrm{hi}}\end{array}$ & $\begin{array}{c}88.87 \pm 0.11^{\mathrm{e}} \\
94.70 \pm 0.39^{\mathrm{bc}} \\
95.75 \pm 0.55^{\mathrm{ab}}\end{array}$ & $\begin{array}{l}93.14 \pm 0.15^{\mathrm{cd}} \\
96.21 \pm 0.27^{\mathrm{ab}} \\
97.13 \pm 0.30^{\mathrm{a}}\end{array}$ \\
\hline \multicolumn{5}{|l|}{ Mass yield (\%) } \\
\hline $1: 5$ & $\begin{array}{l}1 \\
2 \\
3\end{array}$ & $\begin{array}{c}99.37 \pm 0.90^{\mathrm{ab}} \\
99.06 \pm 1.33^{\mathrm{ab}} \\
99.57 \pm 0.52^{\mathrm{a}}\end{array}$ & $\begin{array}{c}98.92 \pm 0.42^{\mathrm{abcd}} \\
99.17 \pm 1.17^{\mathrm{ab}} \\
99.06 \pm 1.25^{\mathrm{ab}}\end{array}$ & $\begin{array}{c}99.02 \pm 1.18^{\mathrm{abc}} \\
99.67 \pm 0.46^{\mathrm{a}} \\
98.89 \pm 0.83^{\mathrm{abcd}}\end{array}$ \\
\hline $1: 10$ & $\begin{array}{l}1 \\
2 \\
3\end{array}$ & $\begin{array}{l}96.48 \pm 1.67^{\text {bcde }} \\
96.48 \pm 0.67^{\text {bcde }} \\
96.77 \pm 1.91^{\text {abcde }}\end{array}$ & $\begin{array}{c}96.07 \pm 1.03^{\text {cdef }} \\
96.83 \pm 0.50^{\text {abcde }} \\
96.38 \pm 1.96^{\text {bcde }}\end{array}$ & $\begin{array}{c}96.99 \pm 1.48^{\text {abcde }} \\
96.78 \pm 1.32^{\text {abcde }} \\
96.03 \pm 0.94^{\text {def }}\end{array}$ \\
\hline $1: 15$ & $\begin{array}{l}1 \\
2 \\
3\end{array}$ & $\begin{array}{c}94.25 \pm 1.16^{\mathrm{efg}} \\
93.08 \pm 1.26^{\mathrm{g}} \\
93.44 \pm 1.55^{\mathrm{fg}}\end{array}$ & $\begin{array}{c}92.95 \pm 1.12^{\mathrm{g}} \\
93.37 \pm 1.10 \mathrm{f}^{\mathrm{g}} \\
92.72 \pm 1.78^{\mathrm{g}}\end{array}$ & $\begin{array}{l}93.13 \pm 1.74^{\mathrm{g}} \\
92.68 \pm 1.10^{\mathrm{g}} \\
92.32 \pm 0.77^{\mathrm{g}}\end{array}$ \\
\hline
\end{tabular}

${ }^{*}$ Mean \pm standard deviation $(n=3)$. For each response, means with different superscript letters are significantly different $(P<0.05)$.

Table 3

Effects of ohmic-assisted esterification (OAE) of hydrolyzed acid oil (HAO) on physical properties of fatty acid methyl esters

\begin{tabular}{ccccc}
\hline $\begin{array}{c}\text { HAO:methanol } \\
\text { molar ratio }\end{array}$ & $\begin{array}{c}\text { Catalyst } \\
\text { concentration } \\
(\%)\end{array}$ & \multicolumn{3}{c}{ Reaction time (min) } \\
\cline { 2 - 4 } & 1 & 5 & 30 & 60 \\
\hline $\begin{array}{c}\text { Kinematic viscosity }\left(\mathrm{mm}^{2} / \mathrm{s}\right) \\
1: 5\end{array}$ & 1 & $10.815 \pm 0.104^{\mathrm{a}^{*}}$ & $8.259 \pm 0.009^{\mathrm{g}}$ & $7.012 \pm 0.004^{\mathrm{k}}$ \\
& 2 & $9.740 \pm 0.003^{\mathrm{c}}$ & $7.297 \pm 0.010^{\mathrm{j}}$ & $6.759 \pm 0.014^{1}$ \\
& 3 & $9.190 \pm 0.012^{\mathrm{d}}$ & $6.733 \pm 0.002^{1}$ & $6.295 \pm 0.008^{\mathrm{n}}$ \\
$1: 10$ & 1 & & \\
& 2 & $10.042 \pm 0.011^{\mathrm{b}}$ & $6.495 \pm 0.002^{\mathrm{m}}$ & $6.100 \pm 0.001^{\mathrm{pq}}$ \\
& 3 & $7.977 \pm 0.038^{\mathrm{e}}$ & $6.264 \pm 0.005^{\mathrm{n}}$ & $6.056 \pm 0.004^{\mathrm{qr}}$ \\
$1: 15$ & & & $6.127 \pm 0.022^{\mathrm{p}}$ & $6.016 \pm 0.004^{\mathrm{r}}$ \\
& 1 & $9.727 \pm 0.003^{\mathrm{c}}$ & $6.187 \pm 0.008^{\mathrm{o}}$ & $6.098 \pm 0.002^{\mathrm{pq}}$ \\
& 2 & $8.522 \pm 0.013^{\mathrm{f}}$ & $6.026 \pm 0.008^{\mathrm{r}}$ & $6.005 \pm 0.004^{\mathrm{r}}$ \\
& 3 & $7.459 \pm 0.064^{\mathrm{i}}$ & $6.014 \pm 0.006^{\mathrm{r}}$ & $6.004 \pm 0.005^{\mathrm{r}}$ \\
\hline
\end{tabular}

Density $\left(\mathrm{kg} / \mathrm{m}^{3}\right)$

$\begin{array}{lllll}1: 5 & 1 & 874.8582 \pm 0.0609^{\mathrm{r}} & 878.0771 \pm 0.0383^{\mathrm{m}} & 879.4229 \pm 0.0005^{\mathrm{j}} \\ & 2 & 876.8731 \pm 0.0008^{\mathrm{p}} & 879.2290 \pm 0.0036^{\mathrm{k}} & 880.3335 \pm 0.0404^{\mathrm{h}} \\ & 3 & 877.7836 \pm 0.0392^{\mathrm{n}} & 879.8157 \pm 0.0015^{\mathrm{i}} & 880.9128 \pm 0.0279^{\mathrm{g}} \\ 1: 10 & & & \\ & 1 & 875.9998 \pm 0.0024^{\mathrm{q}} & 880.8767 \pm 0.0049^{\mathrm{g}} & 881.3099 \pm 0.0076^{\mathrm{e}} \\ & 2 & 877.7591 \pm 0.0085^{\mathrm{n}} & 881.0449 \pm 0.0146^{\mathrm{f}} & 882.0852 \pm 0.0219^{\mathrm{b}}\end{array}$




\begin{tabular}{|c|c|c|c|c|}
\hline & 3 & $878.3333 \pm 0.0253^{1}$ & $881.2993 \pm 0.0087^{\mathrm{e}}$ & $882.2117 \pm 0.2804^{b}$ \\
\hline \multirow[t]{3}{*}{$1: 15$} & 1 & $875.9932 \pm 0.0086^{q}$ & $880.8758 \pm 0.0037^{g}$ & $881.2571 \pm 0.0005^{\mathrm{e}}$ \\
\hline & 2 & $877.1104 \pm 0.0570^{\circ}$ & $881.5832 \pm 0.0410^{\mathrm{d}}$ & $882.1790 \pm 0.0363^{b}$ \\
\hline & 3 & $877.7872 \pm 0.0352^{\mathrm{n}}$ & $881.9469 \pm 0.0047^{\mathrm{c}}$ & $882.4584 \pm 0.0289^{\mathrm{a}}$ \\
\hline \multicolumn{5}{|l|}{ Refractive index } \\
\hline \multirow[t]{3}{*}{$1: 5$} & 1 & $1.3729 \pm 0.0001^{\mathrm{a}}$ & $1.3719 \pm 0.0001^{\mathrm{de}}$ & $1.3716 \pm 0.0000^{\mathrm{fg}}$ \\
\hline & 2 & $1.3723 \pm 0.0001^{b}$ & $1.3718 \pm 0.0001^{\mathrm{def}}$ & $1.3717 \pm 0.0001^{\mathrm{efg}}$ \\
\hline & 3 & $1.3722 \pm 0.0001^{\mathrm{bc}}$ & $1.3717 \pm 0.0001^{\mathrm{efg}}$ & $1.3716 \pm 0.0001^{\mathrm{fg}}$ \\
\hline \multirow[t]{3}{*}{$1: 10$} & 1 & $1.3724 \pm 0.0001^{b}$ & $1.3716 \pm 0.0001^{\mathrm{fg}}$ & $1.3713 \pm 0.0001^{\mathrm{hi}}$ \\
\hline & 2 & $1.3722 \pm 0.0001^{\mathrm{c}}$ & $1.3715 \pm 0.0001^{\mathrm{gh}}$ & $1.3711 \pm 0.0001^{\mathrm{j}}$ \\
\hline & 3 & $1.3719 \pm 0.0001^{\mathrm{de}}$ & $1.3714 \pm 0.0001^{\mathrm{h}}$ & $1.3710 \pm 0.0002^{\mathrm{j}}$ \\
\hline \multirow[t]{3}{*}{$1: 15$} & 1 & $1.3724 \pm 0.0001^{b}$ & $1.3716 \pm 0.0001^{\mathrm{fg}}$ & $1.3714 \pm 0.0001^{\mathrm{h}}$ \\
\hline & 2 & $1.3721 \pm 0.0000^{c}$ & $1.3713 \pm 0.0001^{\mathrm{hi}}$ & $1.3713 \pm 0.0001^{\mathrm{hi}}$ \\
\hline & 3 & $1.3719 \pm 0.0001^{\mathrm{d}}$ & $1.3711 \pm 0.0002^{\mathrm{ij}}$ & $1.3711 \pm 0.0001^{\mathrm{j}}$ \\
\hline
\end{tabular}

${ }^{*}$ Mean \pm standard deviation $(n=3)$. For each response, means with different superscript letters are significantly different $(P<0.05)$.

Table 4

Effects of ohmic-assisted esterification (OAE) of hydrolyzed acid oil (HAO) on color attributes of fatty acid methyl esters

$\begin{array}{ccc}\begin{array}{c}\text { HAO:methanol } \\ \text { molar ratio }\end{array} & \begin{array}{c}\text { Catalyst } \\ \text { concentration }\end{array} & \text { Reaction time (min) }\end{array}$

$(\%)$

$$
5 \quad 30 \quad 60
$$

\begin{tabular}{|c|c|c|c|c|c|}
\hline \multicolumn{6}{|l|}{$\mathrm{L}^{*}$} \\
\hline & \multirow[t]{3}{*}{$1: 5$} & 1 & $49.00 \pm 1.00^{\mathrm{k}^{* *}}$ & $53.50 \pm 0.71^{\mathrm{i}}$ & $55.33 \pm 0.58^{\mathrm{h}}$ \\
\hline & & 2 & $51.50 \pm 0.71^{\mathrm{j}}$ & $57.00 \pm 1.00^{\mathrm{g}}$ & $58.50 \pm 0.71^{\mathrm{ef}}$ \\
\hline & & 3 & $52.50 \pm 0.71^{\mathrm{ij}}$ & $55.50 \pm 0.71^{\mathrm{h}}$ & $57.67 \pm 0.58^{\mathrm{fg}}$ \\
\hline & \multirow[t]{3}{*}{$1: 10$} & 1 & $56.33 \pm 0.58^{\mathrm{gh}}$ & $59.67 \pm 0.58^{\mathrm{de}}$ & $59.00 \pm 1.41^{\mathrm{ef}}$ \\
\hline & & 2 & $58.50 \pm 0.58^{\mathrm{ef}}$ & $60.00 \pm 1.00^{\text {cde }}$ & $61.67 \pm 0.58^{\mathrm{ab}}$ \\
\hline & & 3 & $59.50 \pm 0.71^{\mathrm{de}}$ & $61.50 \pm 0.71^{\mathrm{abc}}$ & $62.00 \pm 1.00^{\mathrm{ab}}$ \\
\hline & \multirow[t]{3}{*}{$1: 15$} & 1 & $56.67 \pm 0.58^{\mathrm{gh}}$ & $60.00 \pm 1.00^{\text {cde }}$ & $61.00 \pm 1.00^{\mathrm{bcd}}$ \\
\hline & & 2 & $58.67 \pm 0.58 \mathrm{ef}$ & $61.00 \pm 1.00^{\mathrm{bcd}}$ & $62.50 \pm 0.71^{\mathrm{ab}}$ \\
\hline & & 3 & $59.33 \pm 0.58^{\mathrm{e}}$ & $61.00 \pm 1.00^{\mathrm{bcd}}$ & $63.00 \pm 1.00^{\mathrm{a}}$ \\
\hline \multicolumn{6}{|l|}{$a^{*}$} \\
\hline & \multirow[t]{3}{*}{$1: 5$} & 1 & $22.00 \pm 1.00^{\mathrm{a}}$ & $19.00 \pm 0.00^{\mathrm{bcd}}$ & $19.00 \pm 1.41^{\mathrm{bcd}}$ \\
\hline & & 2 & $19.50 \pm 0.71^{\mathrm{bc}}$ & $18.50 \pm 0.71^{\mathrm{bcde}}$ & $17.50 \pm 0.71^{\text {cdefg }}$ \\
\hline & & 3 & $18.67 \pm 0.58^{\mathrm{bcd}}$ & $18.00 \pm 1.41^{\text {bcdefg }}$ & $17.50 \pm 0.71^{\text {cdefg }}$ \\
\hline & \multirow[t]{2}{*}{$1: 10$} & 1 & $19.67 \pm 0.71^{\mathrm{b}}$ & $18.00 \pm 1.00^{\text {bcdefg }}$ & $17.67 \pm 1.15^{\text {bcdefg }}$ \\
\hline & & 2 & $18.33 \pm 0.58^{\text {bcdef }}$ & $17.50 \pm 0.71^{\text {cdefg }}$ & $16.50 \pm 0.71^{\text {efgh }}$ \\
\hline
\end{tabular}




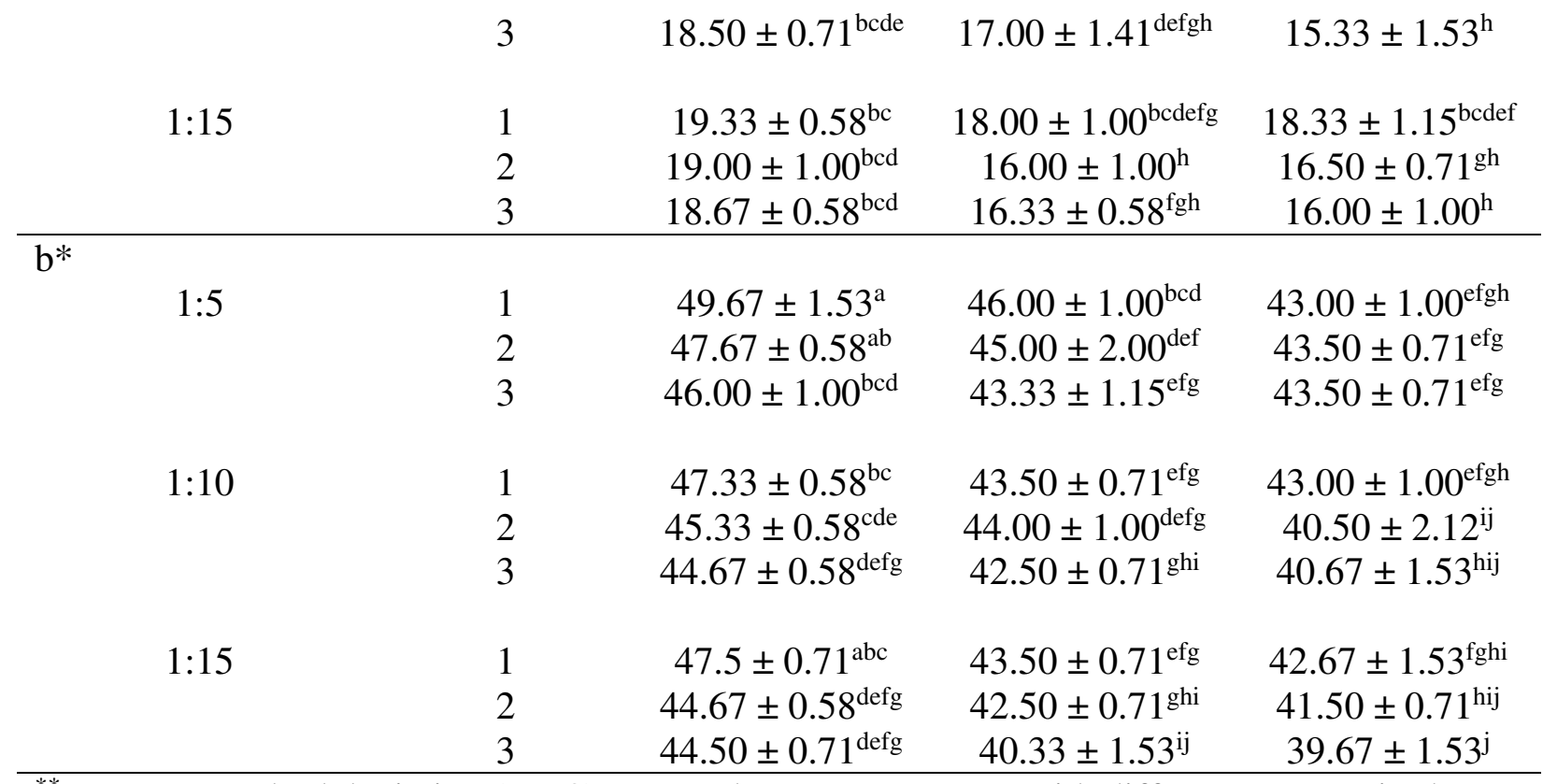

${ }^{* *}$ Mean \pm standard deviation $(n=3)$. For each response, means with different superscript letters are significantly different $(P<0.05)$.

Table 5

Effects of ohmic-assisted esterification (OAE) method on physicochemical properties and energy consumption of fatty acid methyl esters in comparison with conventional esterification (CE) method

\begin{tabular}{lcc}
\hline Parameter & CE $^{* *}$ & OAE $^{* *}$ \\
\hline Physical property & & \\
Kinematic viscosity $\left(\mathrm{mm}^{2} / \mathrm{s}\right)$ & $6.016 \pm 0.005^{\mathrm{a}^{* * *}}$ & $6.016 \pm 0.004^{\mathrm{a}}$ \\
Density $\left(\mathrm{kg} / \mathrm{m}^{3}\right)$ & $882.3224 \pm 0.2782^{\mathrm{a}}$ & $882.2117 \pm 0.2804^{\mathrm{a}}$ \\
Refractive index & $1.3711 \pm 0.0002^{\mathrm{a}}$ & $1.3710 \pm 0.0002^{\mathrm{a}}$ \\
$\mathrm{L}^{*}$ & $61.67 \pm 1.53^{\mathrm{a}}$ & $62.00 \pm 1.00^{\mathrm{a}}$ \\
$\mathrm{a}^{*}$ & $15.67 \pm 1.53^{\mathrm{a}}$ & $15.33 \pm 1.53^{\mathrm{a}}$ \\
$\mathrm{b}^{*}$ & $40.33 \pm 1.53^{\mathrm{a}}$ & $40.67 \pm 1.53^{\mathrm{a}}$ \\
Heating property $\left({ }^{\circ} \mathbf{C}\right)$ & & \\
Flash point & $168.7 \pm 0.6^{\mathrm{a}}$ & $170.0 \pm 1.0^{\mathrm{a}}$ \\
Fire point & $184.3 \pm 1.5^{\mathrm{a}}$ & $186.0 \pm 1.0^{\mathrm{a}}$ \\
Cloud point & $3.5 \pm 0.6^{\mathrm{a}}$ & $3.0 \pm 0.8^{\mathrm{a}}$ \\
Pour point & $-3.25 \pm 0.5^{\mathrm{a}}$ & $-3.75 \pm 0.5^{\mathrm{a}}$ \\
Fatty acid profile $(\%)$ & & \\
Lauric acid & $0.51 \pm 0.05^{\mathrm{a}}$ & $0.54 \pm 0.01^{\mathrm{a}}$ \\
Myristic acid & $1.44 \pm 0.08^{\mathrm{a}}$ & $1.45 \pm 0.04^{\mathrm{a}}$ \\
Palmitic acid & $42.47 \pm 0.38^{\mathrm{a}}$ & $42.14 \pm 0.33^{\mathrm{a}}$ \\
Stearic acid & $1.84 \pm 0.02^{\mathrm{a}}$ & $1.62 \pm 0.01^{\mathrm{b}}$ \\
Oleic acid & $28.21 \pm 0.61^{\mathrm{a}}$ & $27.70 \pm 0.48^{\mathrm{a}}$ \\
Linoleic acid & $24.17 \pm 0.33^{\mathrm{a}}$ & $24.54 \pm 0.48^{\mathrm{a}}$ \\
$\alpha$-Linolenic acid & $1.30 \pm 0.07^{\mathrm{a}}$ & $1.25 \pm 0.07^{\mathrm{a}}$
\end{tabular}




\section{Energy consumption}

Esterification reaction $(\mathrm{kWh})$

$0.070^{\mathrm{a}}$

$0.050^{\mathrm{b}}$

Washing and drying $(\mathrm{kWh})$

$0.018^{\mathrm{a}}$

$0.018^{\mathrm{a}}$

Total (kWh)

$0.088^{\mathrm{a}}$

$0.068^{\mathrm{b}}$

Specific energy consumption $(\mathrm{kWh} / \mathrm{kg})$

$6.686^{\mathrm{a}}$

$5.167^{\mathrm{b}}$

** OAE and CE methods were conducted under optimum condition (hydrolyzed acid oil:methanol molar ratio of $1: 10,3 \%$ catalyst concentration, and 60 min reaction time).

*** Mean \pm standard deviation $(n=3)$; in each row, mean values with different superscript letters are significantly different $(P<0.05)$.

\section{Figure captions:}

Fig. 1 Ohmic-assisted esterification reactor used in this study

Fig. 2 Effects of (a) hydrolyzed acid oil (HAO) to methanol molar ratio (without acid catalyst) and (b) catalyst concentration (at different HAO to methanol molar ratios) on electrical conductivity

Fig. 3 Effects of (a) ohmic-assisted esterification (OAE) and (b) conventional esterification (CE) methods on free fatty acid (FFA) content, purity, and yield of fatty acid methyl esters production under optimum condition (hydrolyzed acid oil:methanol molar ratio of 1:10, 3\% catalyst concentration, and $60 \mathrm{~min}$ reaction time)

Fig. 4 Effects of ohmic-assisted esterification (OAE) and conventional esterification (CE) methods on thermal profile of fatty acid methyl esters production 
Figures

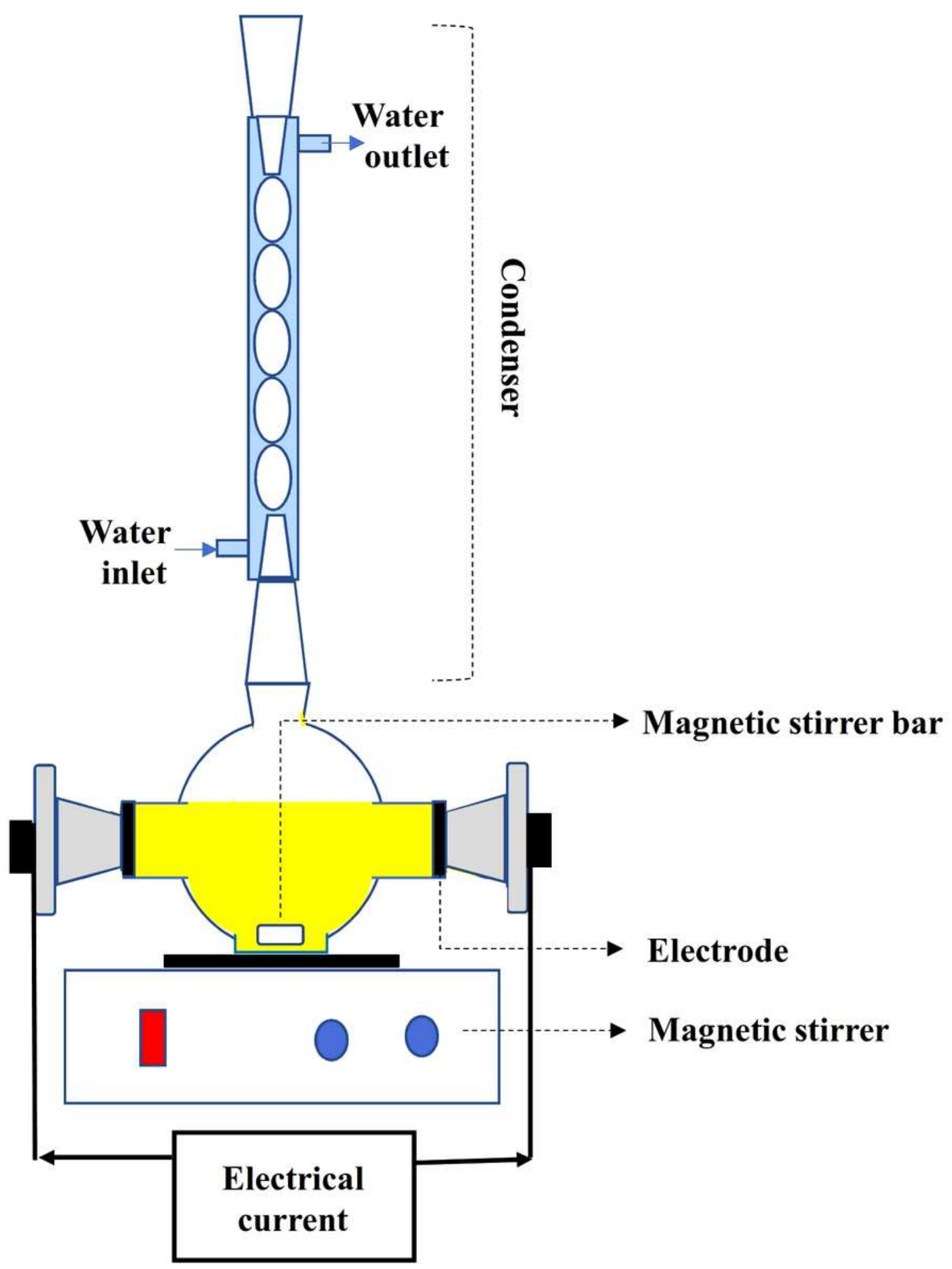

Figure 1

Ohmic-assisted esterification reactor used in this study 

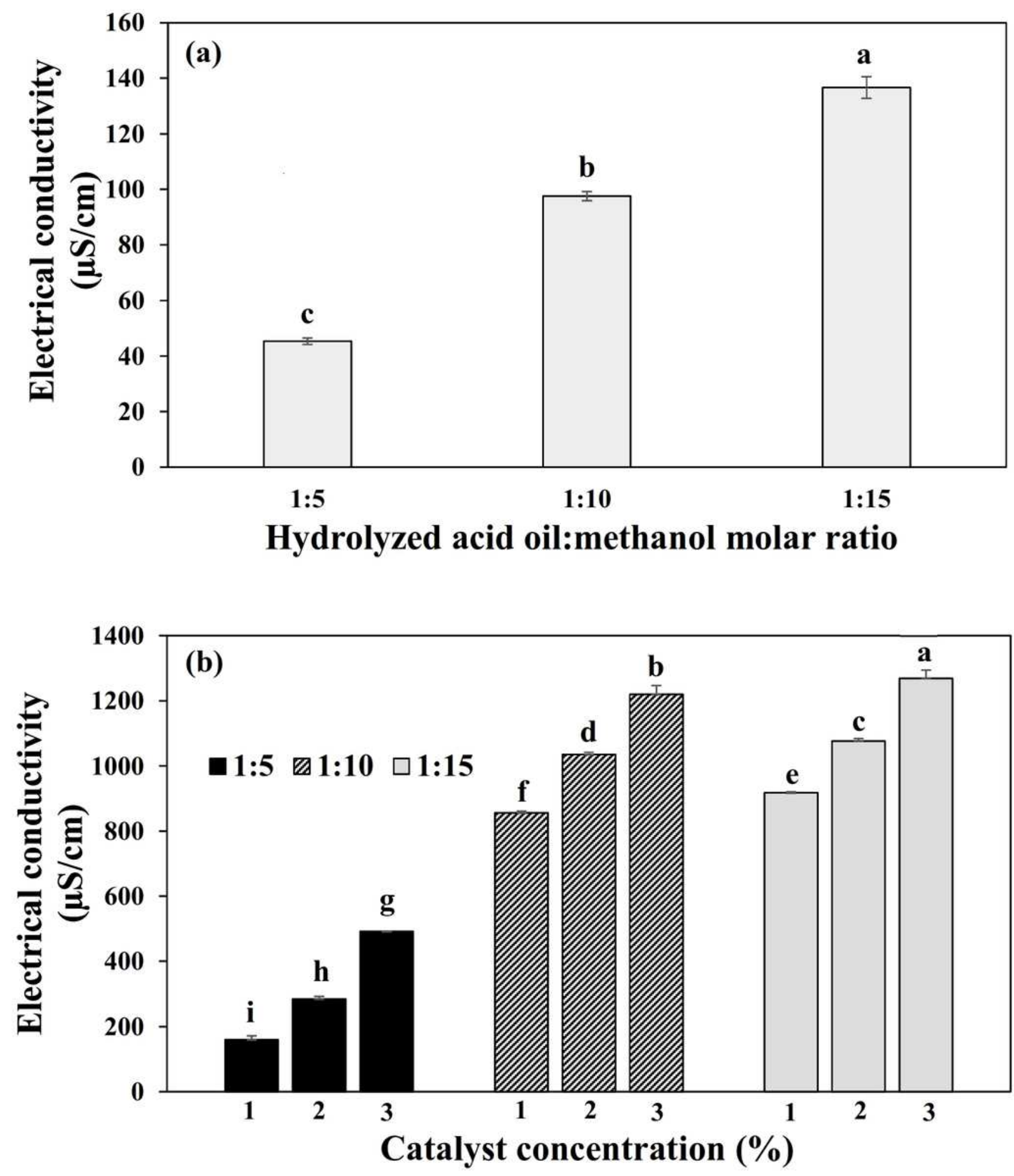

Figure 2

Effects of (a) hydrolyzed acid oil (HAO) to methanol molar ratio (without acid catalyst) and (b) catalyst concentration (at different $\mathrm{HAO}$ to methanol molar ratios) on electrical conductivity 

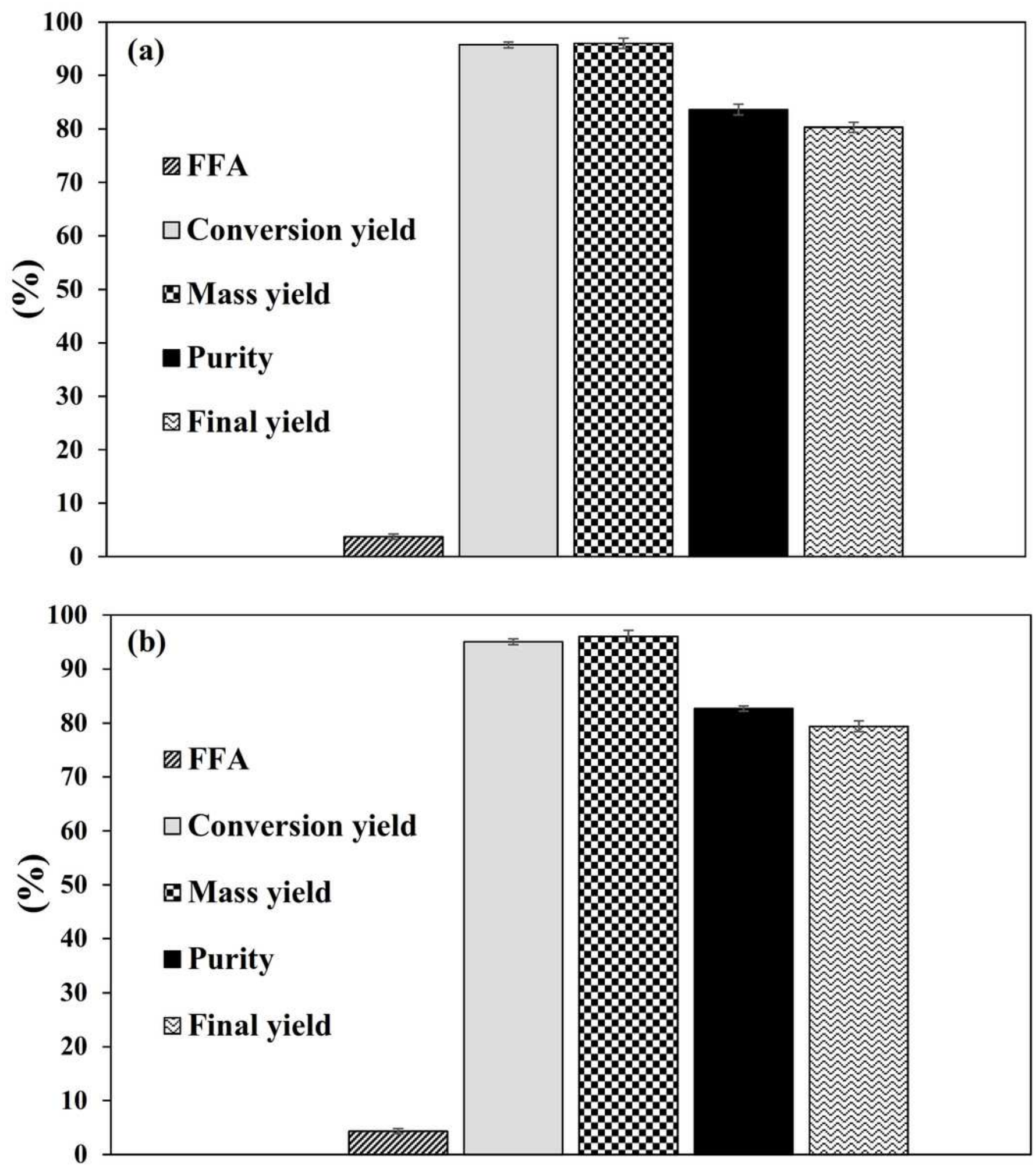

Figure 3

Effects of (a) ohmic-assisted esterification (OAE) and (b) conventional esterification (CE) methods on free fatty acid (FFA) content, purity, and yield of fatty acid methyl esters production under optimum condition (hydrolyzed acid oil:methanol molar ratio of 1:10, 3\% catalyst concentration, and 60 min reaction time) 


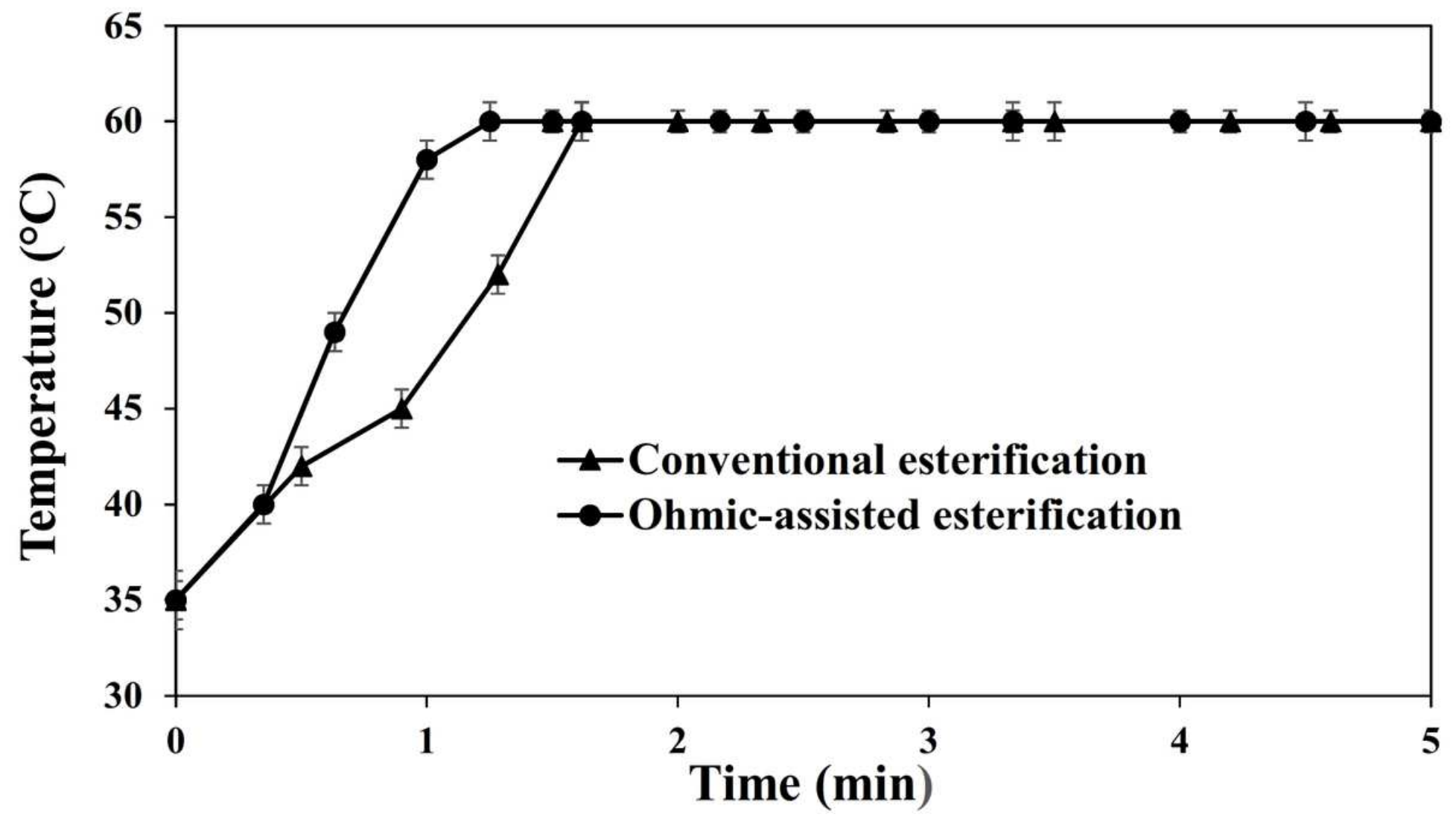

Figure 4

Effects of ohmic-assisted esterification (OAE) and conventional esterification (CE) methods on thermal profile of fatty acid methyl esters production

\section{Supplementary Files}

This is a list of supplementary files associated with this preprint. Click to download.

- GraphicalAbstarctR0.jpg

- HighlightsR0.docx 